British Journal of Education, Society \&
Behavioural Science
10(4): 1-10, 2015, Article no.BJESBS.19449
ISSN: 2278-0998
SCIENCEDOMAIN international
Www.sciencedomain.org

\title{
Time Perspective, Hope, and Learning Strategy among Rural Australian University Students
}

\author{
Justin Ganzer ${ }^{1}$, Nerina J. Caltabiano ${ }^{1 *}$ and Karim Hajhashemi ${ }^{2}$ \\ ${ }^{1}$ Discipline of Psychology, College of Healthcare Sciences, James Cook University, P.O.Box 6811, \\ Cairns, QLD. 4870, Australia. \\ ${ }^{2}$ College of Arts, Society and Education, James Cook University, Australia.
}

Authors' contributions

This work was carried out by author JG under the supervision of author NJC. Authors NJC and KH collaborated in the creation and editing of the manuscript. All authors read and approved the final manuscript.

Article Information

DOI: 10.9734/BJESBS/2015/19449 Editor(s):

(1) Eleni Griva, University of Western Macedonia, Greece. Reviewers:

(1) Linda De Wet, Department of Soil, Crop and Climate Sciences, University of the Free State, South Africa.

(2) Giovana Reis Mesquita, Psychology Department, Federal University of Bahia, Brazil.

(3) Jones Osasuyi Orumwense, Wellspring University, Nigeria. Complete Peer review History: http://sciencedomain.org/review-history/10159

Original Research Article

Received $10^{\text {th }}$ June 2015

Accepted $4^{\text {th }}$ July 2015

Published 14 ${ }^{\text {th }}$ July 2015

\section{ABSTRACT}

Research seeking to improve retention at Universities has traditionally had a focus on student engagement. Temporal orientation has been theorised as having a significant influence on student engagement. Zimbardo's Time Perspective Inventory, the State Hope Scale, and the Study Process Questionnaire were completed by 167 Psychology students attending a rural university. Future Time Perspective and Past Positive were positively correlated with the Hope Pathway subscale. Present Hedonistic Time Perspective was positively correlated with the Agency subscale of Hope. There was a significant difference between deep and surface learners with regards to Future Time Perspective. No significant differences between school leavers and mature-aged students were found for the variables of Time Perspective and Hope. School leavers utilized surface learning strategies, while mature-aged students tended to use deep learning strategies. Current research suggests time perspectives may be helpful in enhancing and supporting academic engagement and persistence in higher education. 
Keywords: Student engagement; surface learners; deep learners; school leavers; mature-aged students; time perspective.

\section{INTRODUCTION}

Retention and participation of students has been a research focus within the field of higher education for four decades now. Participation rates are important to Universities as they are often seen as measures of institutional health $[1,2]$. Historically, issues with retention were seen as a result of the student's inadequacies; the student did not have the perseverance or motivation for the rigors of Academia [2-4]. Research has focused primarily on the first-year experience of students as this is seen as a time that influences academic behaviours [2,5]. Students who withdraw in later years have identified influential events in their first year that affected their choice to withdraw from study [5]. A 2010 survey conducted with Australasian students showed a decrease in first year departure, but an increase in departure intent in later years [6]. A number of studies have investigated student retention and engagement in higher education, from which engagement has emerged as a key issue for continued participation in higher education $[2,5,7,8]$. Academic engagement is assumed to be influenced by motivation and goals [3,7,9-11]. Different researchers have investigated other variables and their influence upon motivation and academic success such as learning strategies [12-14], hope [15-17], and temporal orientation [18-23]. This study focuses on the factors of hope, time orientation and their influence on academic engagement within a rural Australian University.

In 2007, Horstmanshof and Zimitat conducted a study examining the relationships between Time Perspective and variables of academic application and academic orientation in a sample of first year university students. The focus of their research was to identify differences between traditional school leaver students and mature age students, so two categories were defined as those younger than 25 years of age, and those older than 25 years of age respectively. The current study seeks to further inform this line of research within a rural sample of university students.

When investigating student retention and persistence within the field of educational psychology, the issue of engagement is considered a core concept. Engagement can be defined as the result of successful academic and social integration within the university environment [24]. Other theorists, such as Mclnnis, James and Hartley [25], view engagement as a combination of elements such as intellectual application, diligence and participation. Perhaps Astin [3] explained engagement best as he saw engagement as the amount of physical and psychological energy students devote to their academic pursuits. Within the context of this study, engagement will focus on cognitive-motivational components such as surface processing or deeper processing strategies [see 26]. Ultimately students' learning behaviour gets modified depending on their preparedness to persist with the difficulty the task presents. For the purposes of this study, engagement will be defined, and measured, as positive behaviours of deep learning strategies where learning strategy is a concept first popularised by Marton and Säljö $[9,12,14,27]$.

While engagement can be described as motivation towards academic tasks, traditional concepts of motivation are not suitable to explain success and achievement in academic settings [11]. Students are seen as learning agents able to act to achieve their goals [28], while motivation as a concept is related to the future. Being motivated means striving for goals that are by definition as yet not achieved $[10,29]$. As Phalet et al. [10] pointed out, schooling is a futureoriented investment. Traditional interpretations of motivation are not equipped to explain motivation for success in the distant future, dependent upon contingent successes in the present and near future $[11,22,23,30]$. An achievementmotivational theory explains how students can view their current actions and successes as instrumental to future success and outcomes; such as passing introductory subjects influence completion of their degree, and eventual professional registration [11]. Other factors investigated for their effects on student motivation are hope and goal-related beliefs; such as the sense of successful determination in meeting goals in the past, present and future found in Hope theory. The concept of hope is a cognitive-appraisal process of goal-related capabilities, an enduring disposition that is subjectively defined as people assessing their capabilities related to their goals [31].

An important element of achievement-motivation is time, particularly the future. In recent years a number of studies have examined the 
relationship between time orientation and academic success and motivation [5,15,1820,32-34], with significant relationships emerging between motivation and future time perspective [35]. Zimbardo and Boyd [36] proposed a theory of time orientation which they named Time Perspective [5]. They hypothesised Time Perspective to be a non-conscious process whereby the continual flow of personal and social experience is assigned to temporal categories, or time frames which give coherence, order, and meaning to events from which an individual can develop a preference for cognitive-temporal orientation. This cognitive temporal orientation can be thought of as a disposition that influences how an individual responds across a range of daily stimuli $[35,36]$. Time perspective can be considered an individual difference that exerts a dynamic influence on many important judgements, decisions, and actions [36]. Orientations formed as part of past experiences influence acts in the present, and expectations of the future, especially in relation to value and cost of present actions connected to future rewards [5]. It can be argued that there may be differences between school leavers and mature-aged students in how time orientation affects their academic engagement.

Simons, Vansteenkiste, Lens and Lacante [37] reported students who viewed their current course as being of value to future success showed greater motivation and attained better grades than those who perceived their course as a present-orientated task. They suggested having a future orientated time perspective is associated with better performance, increased persistence, and deep conceptual thinking. A study conducted by De Volder and Lens [33] found similar results, 'when students ascribed higher valence to goals in the distant future, and higher instrumental value to studying hard for reaching goals in the distant future, they will be more persistent in their studying and obtain better academic results' [33]. Future orientation appears to be positively associated with positive learning strategies such as deep learning [27]. Learning strategies are seen as stable individual preferences towards the process of learning [38]. The effective use of cognitive and self-regulative strategies is considered an important part of learning strategies [10]. Deep-level learning strategies have been associated with enhanced performance and greater academic engagement $[10,14,27]$.

This study seeks to investigate how learning strategies, hope and time orientation influence academic engagement, and whether there are differences between school-leavers and matureage students. It was predicted that under-25 and over-25 year olds would differ on measures of academic engagement based on learning strategies and hours devoted to study. Furthermore differences in time perspective and hope scores would be observed between the groups. It is hypothesised that similar to established research [33,37], students who maintain deep learning strategies will be predominately future orientated and have higher hope scores than those with surface learning strategies.

\section{METHODS}

\subsection{Participants}

Students from a regional university $(n=167)$ of which 74 percent were female, and 59.3 percent belonged to the under 25 age group ( $n=99$ ) participated in the study. Undergraduate psychology students in first and second year classes were targeted and rewarded by research participation credits. A snowball recruitment method was used to obtain the volunteer sample. All participants completed a single survey comprising three self-report measures and some demographic items.

\subsection{Materials}

The survey consisted of three measures and several demographic items including how many hours you devote to study, what is your current year level, and have you previously completed a degree.

The Zimbardo Time Perspective Inventory (ZTPI) [36] is a 56-item measure consisting of five subscales, Past Negative, Past Positive, Present Hedonistic, Present Fatalistic, and Future. Participants self-report to questions using a fivepoint Likert scale (1 = very uncharacteristic; $5=$ very characteristic). The measure provides an orientation of an individual's time perspective, with the higher score on a scale indicating the dominant time perspective. Zimbardo and Boyd [36] have reported internal consistency estimates for subscale scores based on Cronbach alphas ranging from .74 to .82 (Mdn $\mathrm{a}=.79$ ). The Cronbach alphas for the subscales of the Zimbardo Time Perspective Inventory for the current study are found in Table 1.

The State Hope Scale (SHS) [17,31] was developed to assess an individual's current goal- 
directed thinking. The measure is a 12-item selfreport survey consisting of two subscales, Agency and Pathway. Four items assess agency and four items assess pathway using an eightpoint Likert scale. Responses range from 1 (definitely false) to 8 (definitely true). Four filler items are included in the measure. Internal reliability has been assessed with Cronbach alphas of .74 to .88 [31]. Previous research has found Cronbach alphas for the subscales to be .81 for Agency and .74 for Pathway [17]. The total reliability for the State Hope Scale was found to have an internal reliability coefficient alpha of .86. The total score is a summation of the two subscales. The Cronbach alphas for the State Hope Scale for the current study are found in Table 1.

Table 1. Cronbach alphas for all subscales used in the current study

\begin{tabular}{ll}
\hline Subscales & $\begin{array}{l}\text { Cronbach } \\
\text { alphas }\end{array}$ \\
\hline Zimbardo time perspective & \\
inventory & .81 \\
Past negative & .74 \\
Past positive & .83 \\
Present hedonistic & .72 \\
Present fatalistic & .79 \\
Future & \\
State hope scale & .78 \\
Agency & .82 \\
Pathway & .86 \\
Total state hope scale & \\
Study process questionnaire & .30 \\
Surface motivation & .58 \\
Surface strategy & .80 \\
Deep motivation & .70 \\
Deep strategy & .74 \\
Achieving motivation & .68 \\
Achieving strategy & \\
\hline
\end{tabular}

A shortened version of the Study Process Questionnaire (SPQ) [39] was utilised for the current study. The measure consists of 18 selfreport items. Answers are recorded using a fivepoint Likert scale (1=rarely true, 5= usually true). The shortened version utilises three items representing each of the 6 subscales of the SPQ; Surface Motivation, Surface Strategy, Deep Motivation, Deep Strategy, Achieving Motivation, Achieving Strategy. 'Also present are three second order shared indicator factors (surface, deep and achieving) and one higher order deepachieving factor' [39]. Rote learning is considered to be a surface approach to learning. Someone who is widely read and is able to integrate current knowledge with past knowledge is using a deep approach to learning. The achieving approach to learning is characteristic of someone who is trying to create time and space to successfully achieve. Internal consistency of the subscales was assessed using Cronbach alphas. The following alpha coefficients were reported by Fox et al. [39]; .29 for Surface motive, .51 for Surface strategy, .73 for Deep motive, .53 for Deep Strategy, .65 for Achieving motive, and .64 for Achieving strategy. The Cronbach alphas for the Study Process Questionnaire subscales for the current study are found in Table 1.

\subsection{Procedure}

Ethical clearance was obtained from the home institution before participants were allowed access to the online survey hosted on SurveyMonkey. Participants requiring course credit completed the survey through the webbased human subject pool management software SONA Systems. The use of this software allowed students to be credited for participation and redirected to the SurveyMonkey.com site to complete the survey. This ensured research participation points could be granted while maintaining anonymity.

Descriptive statistics were performed for the variables of interest. Preliminary assumption testing was conducted to check for normality, linearity, univariate and multivariate outliers, homogeneity of variance-covariance matrices, and multicollinearity. The assumption of normality was violated by several variables. A test of normality was conducted using the Kolmogorov-Smirnov statistic for which several variables returned a significant result. Due to this violation of normality non-parametric tests were used for the analysis of the data. Correlational analyses were undertaken to examine the intercorrelations of the measures. A One-way between-group multivariate analysis of variance was conducted as this test is robust enough to accommodate minor violations of assumptions such as normality.

\section{RESULTS}

The mean score for hours spent studying or preparing for University for under 25 year old students was 20.46 hours $(S D=12.55)$, and for over 25 year olds the mean was 23.87 hours $(S D=14.63)$. Table 2 presents the mean scores for the total sample and the respective age groups on the measures used in the study. The data were manipulated so as to determine each student's dominant SPQ learning strategy. 
Significant correlations of measures can be found in Table 3. This is an important preliminary step in examining associations among variables and identifying predictor variables. Only significant correlations greater than .30 are included in Table 3. Future time perspective was examined in relation to other variables due to the positive significant correlations identified and the assumption that future orientation is a likely predictor of positive learning strategies and academic engagement.

Table 4 presents the correlations between ZTPI subscales scores and the other variables. As expected Future time perspective and Past Positive were positively correlated with Hope (SHS) $(r=.37$ and $r=.30)$. Past Negative and
Present Fatalistic were negatively correlated with Hope (SHS) at below a .3 level. For the subscale variables of Past Positive and Future were correlated to the Agency sub-scale ( $r=.34$ and $r=.47$ ). The Pathway subscale of Hope demonstrated a positive correlation with Present Hedonistic time perspective $(r=.30)$. The strongest correlations supported in the study were associated with Future time perspective and the other variables. Future time perspective correlated positively with the measure of Hope $(r=.37)$, and the Agency subscale $(r=.47)$, and Study strategies (SPQ, Deep $(r=.41)$ and Achieving $(r=.43))$; a weak negative nonsignificant correlation was found for the SPQsurface $(r=-.12)$.

Table 2. Means and standard deviations for the total sample and the two age groups

\begin{tabular}{lllllll}
\hline \multirow{2}{*}{ Variables } & \multicolumn{2}{c}{ Total } & \multicolumn{2}{c}{$\mathbf{2 5 s}$} & \multicolumn{2}{c}{$<\mathbf{2 5 s}$} \\
\cline { 2 - 7 } & $\mathbf{M}$ & SD & $\mathbf{M}$ & SD & M & SD \\
\hline Hours spent studying & 21.85 & 13.50 & 20.46 & 12.55 & 23.87 & 14.64 \\
SPQ-surface & 17.42 & .33 & 18.55 & 3.97 & 15.78 & 4.08 \\
SPQ-achieve & 20.44 & .39 & 18.68 & 5.17 & 18.63 & 5.28 \\
SPQ-deep & 20.44 & .39 & 19.59 & 5.15 & 21.68 & 4.75 \\
Hope & 50.23 & 7.59 & 49.61 & 8.03 & 51.13 & 6.84 \\
Hope- agency & 24.80 & .34 & 24.46 & 4.38 & 25.28 & 4.26 \\
Hope- pathway & 25.43 & .31 & 25.14 & 4.41 & 25.85 & 3.41 \\
Future & 45.62 & .53 & 45.13 & 7.23 & 46.35 & 6.18 \\
Present fatalistic & 19.76 & .40 & 20.16 & 5.05 & 19.18 & 4.64 \\
Present hedonistic & 47.74 & .63 & 48.07 & 8.09 & 47.26 & 8.18 \\
Past negative & 28.87 & .50 & 28.95 & 6.49 & 28.75 & 6.37 \\
Past positive & 29.84 & .37 & 30.32 & 4.46 & 29.14 & 5.02 \\
\hline
\end{tabular}

Table 3. Pearson product-moment correlations between measures

\begin{tabular}{lllllll}
\hline Measure & \multicolumn{3}{l}{} & & \\
\hline & $\mathbf{1}$ & $\mathbf{2}$ & $\mathbf{3}$ & $\mathbf{4}$ & $\mathbf{5}$ & $\mathbf{6}$ \\
\hline 1. Hours devoted to study & - & $.37^{* *}$ & $.31^{* *}$ & $.34^{* *}$ & $.21^{* *}$ & $.18^{*}$ \\
2. Future time perspective & & - & $.47^{* *}$ & $.59^{* *}$ & $.48^{* *}$ & $.37^{* *}$ \\
3. SPQ- deep & & & - & $.54^{* *}$ & $.38^{* *}$ & $.38^{* *}$ \\
4. SPQ- achieving & & & - & $.39^{* *}$ & $.31^{* *}$ \\
5. SHS- agency & & & & - & $.91^{* *}$ \\
6. SHS- total & & & & & - \\
\hline
\end{tabular}

Table 4. Pearson product-moment correlation of time perspectives with other measures

\begin{tabular}{llllllll}
\hline Measure & Agency & Pathway & $\begin{array}{l}\text { Hope } \\
\text { total }\end{array}$ & $\begin{array}{l}\text { SPQ- } \\
\text { deep }\end{array}$ & $\begin{array}{l}\text { SPQ- } \\
\text { surface }\end{array}$ & $\begin{array}{l}\text { SPQ- } \\
\text { achieving }\end{array}$ & $\begin{array}{l}\text { Hours } \\
\text { devoted } \\
\text { to study }\end{array}$ \\
\hline Past positive & $.34^{* *}$ & $.20^{* *}$ & $.30^{* *}$ & .03 & .07 & .07 & -.08 \\
Past negative & $-28^{* *}$ & $-.17^{* *}$ & $-.25^{* *}$ & $-.17^{* *}$ & -.06 & -.01 & .14 \\
Present hedonistic & $-.16^{*}$ & $.30^{* *}$ & $.25^{* *}$ & -.05 & -.03 & .07 & -.02 \\
Present fatalistic & $-.26^{* *}$ & $-.23^{* *}$ & $-.27^{* *}$ & $-.21^{* *}$ & .12 & -.14 & -.03 \\
Future & $.47^{* *}$ & $.19^{*}$ & $.37^{* *}$ & $.41^{* *}$ & -.12 & $.43^{* *}$ & $.37^{* *}$ \\
\hline \multicolumn{7}{c}{${ }^{*} p<.05 ;{ }^{* *} p<.01$ (two-tailed) } \\
\end{tabular}


A Kruskal-Wallis test was utilised to assess any differences between Future time perspective and dominant learning strategy profiles identified by the SPQ scores. Students $(n=133)$ were allocated into three groups according to their dominant learning strategy (Deep, Surface, and Achieving); expressed by the individuals' highest scores on the SPQ. There was a statistically significant difference in Future time perspective across the three different learning strategy groups (Deep $(n=36)$, Surface $(n=24)$, and Achieving $(n=73)), X^{2}(3, n=133)=8.36, p=$ .015. The Deep strategy group recorded a higher median score $(\mathrm{Md}=49.69)$ than the other two age groups. Mann-Whitney $U$ tests were conducted to further investigate the results and identify which learning strategy groups were significantly different from one another. A Bonferroni adjusted alpha level of .017 was used to control for Type 1 errors. The Mann-Whitney $U$ test identified a significant difference between the Deep $(\mathrm{Md}=49.69, \mathrm{n}=36)$ and Surface strategy (Md= 40.81, $n=24)$ groups; $U=249.50$, $z=-2.75, p=.006, r=.35$.

To determine whether there were any differences between the under 25 age group and the over 25 year olds, Mann-Whitney $U$ tests were conducted for time perspective (Past Negative, Past Positive, Present Hedonistic, Present Fatalistic, and Future) scores, the total State Hope Scale scores and its individual subscales of Pathway and Agency. There were no significant differences between scores for under-25 year old students and the over-25 year old students on each of the dependent variables.

A one-way between groups multivariate analysis of variance was undertaken to analyse age group differences in learning strategy measured by the SPQ subscales (Deep, Surface and Achieving). There was a statistically significant difference between under 25 year old students and students over-25 years of age on the combined dependent variables, $F(3,164)=$ 9.25, $p<.001$; Wilks' Lambda $=.85$; partial eta squared $=.15$. When the results of the dependent variables were considered separately two variables reached statistically significant levels, using a Bonferroni adjusted a level of .017. The variables were Surface subscale $F(1,163)=$ $14.49, p=<.001$, partial eta squared $=.08$ and Deep subscale, $F(1,163)=14.12, p<.001$, partial eta squared $=.079$. An investigation of the mean scores indicated that the under-25 students had a higher representation of participants utilising a Surface learning strategy $(M=8.38, S D=2.65)$, while the over-25 years old students have a higher tendency for the Deep learning strategy $(M=10.69, S D=2.49)$.

Hierarchical multiple regression was used to assess the ability of Future time perspective and SHS to predict engagement as identified by the SPQ deep subscale, after controlling for the influence of age. Age was entered at Step 1, explaining eight percent of the variance in the dependent variable of engagement. After entry of Future time perspective and SHS at Step 2, the total variance explained by the model as a whole was 26 percent, $F(3,163)=19.12, p<.001$. Future time perspective and SHS scores explained an additional 18 percent of the variance in engagement after controlling for age, $R$ squared change $=.18, F$ change $(2,163)=$ $19.99, p<.001$. In the final model all variables were statistically significant, with Future scoring the highest beta value (beta $=.32, p<.001$ ) then Age (beta $=.25, p<.001$ ) followed by SHS (beta $=.19, p=.010)$.

\section{DISCUSSION}

The evidence ascertained in the study highlights three main points: The positive effect of Future time perspective on students' academic engagement, significant differences in learning strategy use by those over 25 and under 25 years of age, and the predictive validity of Future time perspective and hope scores for academic engagement. A further point evident within the study was the lack of significant differences observed between age groups for time perspective and a lack of significant differences in Hope.

Statistically significant positive relationships were found between academic engagement, as measured by Deep strategy, and Future time perspective and Hope. In particular, orientation to the future emerged as the strongest single predictor for academic engagement (Deep SPQ) and variables of Hope-Agency and total Hope scores. Higher Future orientation was related to an increase in Deep strategy use, suggesting students who were future orientated engaged in increased positive study behaviours and used Deep strategy processes. In terms of the current study this is seen to measure greater academic engagement. Future time perspective was also positively, statistically significantly correlated with variables of hope; Total Hope Scores and 
Agency. The subscale of Agency's correlation with Future time perspective implies students who are Future orientated are more motivated to reach their goals. Agency was also positively correlated with the measure of academic engagement. Students who felt determined to reach their goals were more likely to engage in Deep learning strategies. The subscale variable of Pathway demonstrated statistically significant correlations at weak levels (below .30) to Future and academic engagement. This subscale refers to a sense of being able to generate successful plans to meet goals, which suggest that the cognitions of Pathway and Agency are activated within Future Time Perspective and academic engagement; the determination to meet goalsAgency- has a greater influence. These findings are similar to established research within the field as Future time perspective has been found to be positively correlated with measures of academic success, academic orientation and academic achievement [5, 18], and measures of Hope; including the subscale of Agency and Pathway [18].

The nature of the relationship between Future time perspective and learning strategies was examined by utilising the non-parametric procedure of Kruskal-Wallis testing. Within the sample dominant learning strategy profiles of Deep, Surface and Achieving were observed. These profiles related to expressed preferences measured by their highest score of the SPQ subscales. There was a statistically significant difference in Future time perspective across the three different learning strategy groups. When this relationship was investigated with the use of Mann-Whitney test procedures Future orientation was greater for the Deep profile. This further supports the relationship identified by the correlation investigation and is consistent with current research [5]. Theorists such as Astin [3] and Tinto [2] have suggested engagement is influenced by social, economic, cultural and psychological elements. Based on the literature, Time Perspective might be included as another psychological influence on academic engagement and success. Established theories suggest cognitions relevant to deep strategy use are characteristic of engaged students, with students who use deep strategies more likely to achieve academically $[2,3,8,16]$. Similar findings have suggested strengthening students' orientation to the future might increase engagement to academic activities students take part in. Furthermore, a future orientation based intervention may positively influence a student's long-term engagement $[5,15]$. As recommended by Tinto [2], intervention strategies are best implemented as part of the curriculum rather than as additional components of the educational experience [5]. At present, universities devote substantial amounts of attention and resources to facilitate student engagement. Typically these programs are run as additional interventions targeting students at-risk of drop out [1,2]. A finding from current literature is students display tendencies to become increasingly surface and decreasingly deep in their orientation to learning [13].

Age has also been identified as another important variable related to engagement, with deeper approaches to learning observed more by older students $[5,40]$. In the present study the key age-related difference was learning strategy used. The under 25 age group was identified as having increased surface tendencies, while the over 25 age group showed an increased use of deep learning strategies. Krause, Hartley, James, and Mclnnis [41] reported mature-age students were more strategic about managing workload, have a stronger sense of purpose about their future occupation, and appear to work more independently than younger students $[5,41]$. While it appears older students are better students, attrition rates for older students are higher than their younger counterparts [5], which could be a result of other social factors and stressors placed upon older individuals.

Gender differences should be investigated in relation to the study variables, even though some studies suggest that gender does not play a role in engagement [16] while others have demonstrated gender-based differences [35]. Gender was not included in the present study due to the disproportionate sample possessing a greater number of females who participated in the study. However, this is not only related to the university which the sample in this study was taken, but indicative of Australian university gender makeup. Males are underrepresented at universities in Australia with ratios often quoted as two males to every three females [8]. With a greater number of male participants, genderbased differences may well have been observed in relation to Time Perspective.

A further benefit of an increased sample size could be the investigation of the variables across different disciplines and year levels, as Biggs et al. [13] observed that as students went further 
into their degrees, they tended to become more surface strategic. Although surface strategy users can and do achieve academically, deep learners are usually associated with higher academic successes $[8,14]$.

\section{CONCLUSION}

This study contributes to the current research and literature concerning factors influencing academic engagement of psychology students at a tertiary education level. Interrelationships between cognitive and behavioural aspects of engagement and variables of time orientation and Hope- including subscales of Agency and Pathway have been confirmed. Future time perspective was shown to be a predictor of academic engagement as measured by SPQ Deep strategy. These findings can be of use in formulating innovative interventions which can enhance the engagement of diverse student populations, in order to improve their university experience and hopefully, increase retention.

\section{COMPETING INTERESTS}

Authors have declared that no competing interests exist.

\section{REFERENCES}

1. Blunden, R, First year student attrition and the moral responsibility of universities. Journal of Institutional Research, 2002;11 (1):59-70.

2. Tinto, $\mathrm{V}$, Research and practice of student retention: What next?. Journal of College Student Retention: Research, Theory and Practice. 2006;8(1):1-19.

3. Astin, AW, Student involvement: A developmental theory for higher education. Journal of College Student Development, 1999;40(5):518-529.

4. Lawrence $\mathrm{J}$, Re-conceptualising attrition and retention: Integrating thoretical, research and student perspectives. Studies in Learning, Evaluation, Innovation and Development. 2005;2(3):16-33.

5. Horstmanshof L, C Zimitat. Future time orientation predicts academic engagement among first year university students. British Journal of Educational Psychology. 2007;77(3):703-718.
6. Coates H, L Ransom. Dropout DNA, and the genetics of effective support. Australasian Survey of Student Engagement (AUSSE) Briefings. 2011;11.

7. Fredricks JA, Blumenfeld PC, Paris $A H$. School engagement: Potential of the concept, state of the evidence. Review of Educational Research, 2004;74(1):59-109.

8. Yorke $M$, Student engagement: deep, surface or strategic, in Keynote address to the $9^{\text {th }}$ Pacific Rim Conference on the First Year in Higher Education; 2006. Griffith University, Australia.

9. Entwistle N, Mc Cune V, The conceptual bases of study strategy inventories. Educational Psychology Review. 2004; 16(4):325-345.

10. Phalet K, Andriessen I, Lens W, How future goals enhance motivation and learning in multicultural classrooms. Educational Psychology Review. 2004;16 (1):59-89.

11. Raynor JO, Relationships between achievement-related motives, future orientation, and academic performance. Journal of Personality and Social Psychology. 1970;15(1):28-33.

12. Biggs J, What the student does: Teaching for enhanced learning. Higher Education Research \& Development. 2012;31(1):3955.

13. Biggs J, Kember D, Leung DY, The revised two-factor study process questionnaire: R-SPQ-2F. British Journal of Educational Psychology, 2001;71(1): 133-149.

14. Laird TFN, Shoup R, Kuh GD, Deep learning and college outcomes: Do fields of study differ. In Annual Meeting of the Association for Institutional Research; 2005a. San Diego, CA.

15. Brown, WT, Jones JM, The substance of things hoped for: A study of the future orientation, minority status perceptions, academic engagement, and academic performance of black high school students. Journal of Black Psychology. 2004;30 (2):248-273.

16. Phan HP, Amalgamation of future time orientation, epistemological beliefs, achievement goals and study strategies: Empirical evidence established. British Journal of Educational Psychology. 2009; 79(1):155-173. 
17. Snyder CR, et al., Hope and academic success in college. Journal of educational psychology. 2002;94(4):820-826.

18. Adelabu DH, Future time perspective, hope, and ethnic identity among African American adolescents. Urban Education. 2008;43(3):347-360.

19. D'Alessio M, et al., Testing Zimbardo's Stanford Time Perspective Inventory (STPI)-Short Form An Italian Study. Time \& Society. 2003;12(2-3):333-347.

20. Kauffman, DF, Husman J, Effects of time perspective on student motivation: Introduction to a special issue. Educational Psychology Review. 2004;16(1):1-7.

21. Luyckx K, et al. Time perspective and identity formation: Short-term longitudinal dynamics in college students. International Journal of Behavioral Development. 2010; 34(3):238-247.

22. Raynor JO, Future orientation and motivation of immediate activity: An elaboration of the theory of achieve-ment motivation. Psychological Review. 1969;76 (6):606-610.

23. Raynor JO, Rubin IS, Effects of achievement motivation and future orientation on level of performance. Journal of Personality and Social Psychology. 1971;17(1):36-41.

24. Tinto $V$, Leaving college: Rethinking the causes and cures of student attrition; 1993. Chicago: University of Chicago Press.

25. Mclnnis C, James R, Hartley R, Trends in the first year experience in Australian universities; 2000. Canberra: DETYA Higher Education Division.

26. Chapman E. Alternative approaches to assessing student engagement rates. Practical Assessment, Research \& Evaluation. 2003;8.

27. Laird TFN, Shoup R, Kuh GD, Measuring deep approaches to learning using the National Survey of Student Engagement. In Annual Meeting of the Association for Institutional Research; 2005b. Chicago, IL.

28. Zepke, N, Leach L, Butler P, Student motivation and engagement in learning, in $32^{\text {nd }}$ HERDSA Annual conference; 2009. Darwin.

29. Lens, W. and A. Gailly, Extension of future time perspective in motivational goals of different age groups. International Journal of Behavioral Development. 1980;3(1):117.

30. Shell DF, Husman J, Control, motivation, affect, and strategic self-regulation in the college classroom: A multidimensional phenomenon. Journal of Educational Psychology. 2008;100(2):443-459.

31. Snyder CR, et al. The will and the ways: development and validation of an individual-differences measure of hope. Journal of Personality and Social Psychology. 1991;60(4):570-585.

32. Bembenutty $H$, Karabenick SA, Inherent association between academic delay of gratification, future time perspective, and self-regulated learning. Educational Psychology Review. 2004;16(1):35-57.

33. De Volder ML, Lens W, Academic achievement and future time perspective as a cognitive-motivational concept. Journal of Personality and Social Psychology. 1982;42(3):566-571.

34. Husman J, Lens $\mathrm{W}$, The role of the future in student motivation. Educational Psychologist. 1999;34(2):113-125.

35. Worrell FC, Mello ZR, The reliability and validity of Zimbardo Time Perspective Inventory scores in academically talented adolescents. Educational and Psychological Measurement. 2007;67(3): 487-504.

36. Zimbardo PG, Boyd JN, Putting time in perspective: A valid, reliable individualdifferences metric. Journal of Personality and Social Psychology. 1999;77(6):12711288.

37. Simons J, et al., Placing motivation and future time perspective theory in a temporal perspective. Educational Psychology Review. 2004;16(2):121-139.

38. Vermunt JD, Vermetten YJ, Patterns in student learning: Relationships between learning strategies, conceptions of learning, and learning orientations. Educational Psychology Review. 2004;16 (4):359-384.

39. Fox RA, Mc Manus I, Winder BC, The shortened Study Process Questionnaire: An investigation of its structure and longitudinal stability using confirmatory factor analysis. British Journal of Educational Psychology. 2001;71(4):511530. 
40. Beattie IV, V. Collins B, Mcinnes B, Deep and surface learning: a simple or simplistic dichotomy? Accounting Education. 1997;6(1):1-12.

41. Krause $\mathrm{KL}$, et al. The first year experience in Australian universities: Findings from a decade of national studies: Centre for the Study of Higher Education; 2005. University of Melbourne: Melbourne.

(c) 2015 Ganzer et al.; This is an Open Access article distributed under the terms of the Creative Commons Attribution License (http://creativecommons.org/licenses/by/4.0), which permits unrestricted use, distribution, and reproduction in any medium, provided the original work is properly cited.

Peer-review history:

The peer review history for this paper can be accessed here: http://sciencedomain.org/review-history/10159 